\title{
DEVIATION ANALYSIS AND FAILURE DIAGNOSIS OF DIESEL ENGINE
}

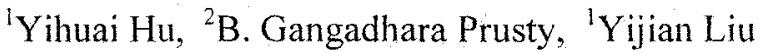 \\ 'Shanghai Maritime University, ${ }^{2}$ University of New South Wales
}

Abstract: A computer-based filling and emptying diesel engine simulation model has been developed, which can simulate the operational behavior of diesel engine under different performance failures and different running conditions. This paper firstly describes the simulation models and simulated results of a fourstroke, turbo-charged diesel engine. The calculated results in terms of relative deviation are analyzed which reveal the relations between thermodynamic variables, performance failures, running conditions and ship operation conditions. Further, it provides more complete understanding of failures" behaviors under different running conditions and help to detect the failures amongst complex symptoms. Relative deviation of thermodynamic variables under different running conditions exhibits strong similarity, which induces a new information source for failure detection. Compared to experiments on board ship, this simulative modeling possesses advantages of shorter studying period, less research investment, lower risk in failure simulation and more symptomatic information. Finally an example is introduced to verify the feasibility of relative deviation analysis in the use of diesel engine failure diagnosis with artificial neural network method.

Key words: deviation analysis, failure diagnosis, diesel engine simulation

\section{INTRODUCTION}

Condition monitoring and failure diagnosis techniques are considered of major importance to higher reliability of machinery and can be of great benefits in reducing manning levels, especially for big and critical systems such as gas turbines, aircraft, nuclear power stations and marine engines. With several unique properties of little disturbance from outside, high 
quality of information, wide range for diagnosis and strong availability in application, thermodynamic variables of marine diesel engine are usually regarded as the most abundant symptomatic source for failure diagnosis. But large bore marine diesel engine is a complex system composted of mechanical, electronic, thermal and hydraulic subsystems. This kind of system always has lots of failure motivating sources and confusing symptoms. So far, most of knowledge about relations between performance failures and thermodynamic variables is mainly from experiments, which is very difficult to be carried out onboard ship. Experimental modeling of big, complex diesel engine for failure diagnosis has been the "bottleneck" in intelligent failure diagnosis of marine diesel engine.

Deviation analysis based on simulation model, proposed in this paper, will give us a more complete understanding of failures' behaviors under different running conditions, help us to detect the failures amongst complex symptoms and, if accurate enough, provide modeling specimen for artificial neural network in failure diagnosis of marine diesel engine.

\section{SIMULATION MODEL}

The engine model referred to in this paper is based on a general purpose engine thermodynamic simulation code ${ }^{[1]}$. This model treats a multi-cylinder engine as a series of thermodynamic control volumes interconnected through valves and ports. Several modifications have been made to meet the demand for failure simulation and performance prediction at different running, which are described in this article.

To take into account the influence of performance failures to combustion procedure, a term called combustion efficiency was introduced into the Wiebe's combustion function ${ }^{[2]}$. The term is defined as the ratio of completely burned fuel and injected fuel, which is the function of excess air factor $\alpha$ defined as ${ }^{[2]}$

$$
\eta_{u}= \begin{cases}3 \alpha / 5 & (\alpha<1.25) \\ (\alpha+1) / 3 & (1.25 \leq \alpha \leq 2) \\ 1 & (\alpha>2)\end{cases}
$$

Then the rate of heat release can be defined as

$$
\frac{d Q_{f}}{d \varphi}=6.908 \frac{\eta_{u} g_{f} H_{u}}{\Delta \varphi}(m+1)\left(\frac{\varphi-\varphi_{V B}}{\Delta \varphi}\right)^{m} e^{-6.908\left(\frac{\varphi-\varphi_{V B}}{\Delta \varphi}\right)^{m+1}}
$$

where the ignition advance angle is

$$
\varphi_{V B}=\theta_{g}+\Delta \theta_{1}+\Delta \theta_{2}
$$

the heat release duration angle is 


$$
\Delta \varphi=\Delta \varphi_{0}\left(\frac{\alpha_{0}}{\alpha}\right)^{0.6}\left(\frac{n}{n_{0}}\right)^{0.5}
$$

the heat release shape factor is

$$
m=m_{0}\left(\frac{\Delta \theta_{20}}{\Delta \theta_{2}}\right)^{0.5}\left(\frac{p_{a}}{p_{a 0}} \frac{T_{a 0}}{T_{a}}\right)\left(\frac{n_{0}}{n}\right)^{0.8}
$$

where $Q_{f}$ :released heat of combussted fueloil;

$\varphi$ : crankshaft rotating angle of diesel engine;

$\theta_{g}:$ fuel injection angle;

$\Delta \theta_{1}$ : injection lag angle;

$\Delta \theta_{2}$ : ignition lag angle;

$\Delta \varphi_{0}$ : heat release duration angle at rated condition with no performance failure;

$\alpha_{0}$ : excess air factor at rated condition with no performance failure;

$\alpha:$ excess air factor at calculated condition;

$n_{0}$ : running speed at rated condition;

$n$ : running speed at calculated condition;

$m_{0}$ : heat release shape factor at rated condition with no performance failure;

$\Delta \varphi_{20}$ : ignition lag angle at rated condition;

$\Delta \varphi_{2}$ : ignition lag angle at calculated condition;

$p_{a 0}$ : chamber pressure at compression stroke's beginning at rated condition;

$p_{a}$ : chamber pressure at compression stroke's beginning at calculated condition;

$T_{a 0}$ : chamber temperature at compression stroke's beginning at rated condition;

$T_{a}$ : chamber temperature at compression stroke's beginning at the calculated condition;

The variables $\Delta \varphi_{1}$ and $\Delta \varphi_{2}$ in equation (3) are defined as:

$$
\begin{aligned}
& \Delta \theta_{1}=\Delta \theta_{10} \frac{n}{n_{0}} \\
& \Delta \theta_{2}=6 n \tau_{i} \times 10^{-3}
\end{aligned}
$$




$$
\tau_{i}=0.1+2.627 e^{\frac{1967}{T}} p^{-0.87}
$$

where $\Delta \varphi_{10}$ : ignition lag angle at rated condition ;

$\tau_{i}:$ ignition delay duration;

$T: \quad$ chamber temperature at compression stroke end;

$p$ : chamber pressure at compression stroke end.

To simulate the scavenging process a three-zone scavenging mode, with fresh air, exhaust gas and mixing zones, was utilized. Turbocharger compressor and turbine experimental performance maps were included in digitized form and the code can interpolate within the data to find the operating point.

Example: A large, medium speed, four-stroke, six-cylinder fish-boat main diesel engine, adapted with a VTR-201 type turbocharger, was chosen to be simulated. Previous publication had formed good agreement of the model prediction with available experimental data ${ }^{[2]}$. By carefully adjustment of the appropriate input data and model coefficients, 14 typical performance failures and 4 ship operation conditions were simulated. The selected input data and model coefficients of simulated failures refereed to the normal condition are presented in Table 1.

Table 1. Input data and model coefficients

\begin{tabular}{|c|c|c|c|c|}
\hline Failure & Performance Failure & & Input Data and Mod & Coefficients \\
\hline Index & Operation Condition & Normal Data & Abnormal Data & Data Descriptions \\
\hline a & $\begin{array}{l}\text { Blocked turbocharger exhaust } \\
\text { casing }\end{array}$ & por $=0.1033(\mathrm{MPa})$ & pot $=0.1074(\mathrm{MPa})$ & turbine outlet Back-pressure \\
\hline $\mathrm{b}$ & Low ambient temperature & $\mathrm{T}_{\mathrm{O}}=27\left({ }^{\circ} \mathrm{C}\right)$ & $T_{0}=-20\left({ }^{\circ} \mathrm{C}\right)$ & $\begin{array}{l}\text { Air inlet temperature of } \\
\text { compressor }\end{array}$ \\
\hline c & High ambient temperature & $\mathrm{T}_{\mathrm{O}}=27\left({ }^{\circ} \mathrm{C}\right)$ & $T_{0}=40\left({ }^{\circ} \mathrm{C}\right)$ & $\begin{array}{l}\text { Air inlet temperature of } \\
\text { compressor }\end{array}$ \\
\hline d & $\begin{array}{l}\text { Blocked air filter of } \\
\text { turbocharger }\end{array}$ & $P_{0}=0.1033(\mathrm{MPa})$ & $\mathrm{P}_{0}=0.095(\mathrm{MPa})$ & $\begin{array}{l}\text { Air inlet pressure of } \\
\text { compressor }\end{array}$ \\
\hline $\mathrm{e}$ & Poorly cooled cylinder liner & $T W=200\left({ }^{\circ} \mathrm{C}\right)$ & $T W=500\left({ }^{\circ} \mathrm{C}\right)$ & $\begin{array}{l}\text { Average temperature on liner } \\
\text { surface }\end{array}$ \\
\hline $\mathrm{f}$ & Poorly cooled piston cap & $T W 1=300\left({ }^{\circ} \mathrm{C}\right)$ & $\left.T W 1=6000^{\circ} \mathrm{C}\right)$ & $\begin{array}{l}\text { Average temperature on } \\
\text { piston head }\end{array}$ \\
\hline g & $\begin{array}{l}\text { High inlet cooling water } \\
\text { temperature of intercooler }\end{array}$ & $\mathrm{CMX0}=45\left(^{\circ} \mathrm{C}\right)$ & $\mathrm{CMX0}=70(\mathrm{C})$ & $\begin{array}{l}\text { Cooling water inlet } \\
\text { temperature of intercooler }\end{array}$ \\
\hline $\mathrm{h}$ & $\begin{array}{l}\text { Low inlet cooling water } \\
\text { temperature of intercooler }\end{array}$ & $\mathrm{CMXO}=45\left({ }^{\circ} \mathrm{C}\right)$ & $\mathrm{CM} \times 0=10\left({ }^{\circ} \mathrm{C}\right)$ & $\begin{array}{l}\text { Cooling water inlet } \\
\text { temperature of intercooler }\end{array}$ \\
\hline$i$ & Deposited air intake manifold & $\mathrm{USM}=0.45$ & USM $=0.15$ & $\begin{array}{l}\text { Air flow coefficient at inlet } \\
\text { port }\end{array}$ \\
\hline $\mathrm{j}$ & $\begin{array}{l}\text { Deposited gas exhaust } \\
\text { manifold }\end{array}$ & UEM $=0.50$ & UEM $=0.20$ & $\begin{array}{l}\text { Aif flow coefficient at output } \\
\text { port }\end{array}$ \\
\hline$k$ & Fouled intercooler on air side & $\begin{array}{l}\mathrm{CMXN}=0.8 \\
\mathrm{CM}=14.8\end{array}$ & $\begin{array}{l}\mathrm{CMXN}=0.35 \\
\mathrm{CM}=8.0\end{array}$ & $\begin{array}{l}\text { Cooling efficiency and } \\
\text { resistance efficient }\end{array}$ \\
\hline 1 & Deposited turbine nozzle & $\mathrm{FC}=0,0054\left(\mathrm{~m}^{2}\right)$ & $\mathrm{FC}=0.0044\left(\mathrm{~m}^{2}\right)$ & $\begin{array}{l}\text { Geometric llow area of } \\
\text { turbine nozzle }\end{array}$ \\
\hline $\mathrm{m}$ & Worn turbocharger bearing & NTM $=0.98$ & NTM $=0.95$ & $\begin{array}{l}\text { Mechanical efficiency of } \\
\text { turbocharger bearing }\end{array}$ \\
\hline$n$ & $\begin{array}{l}\text { Air-blocked inside cylinder } \\
\text { jacket }\end{array}$ & $\mathrm{CJ}=1,0$ & $\mathrm{CJ}=0.25$ & $\begin{array}{l}\text { Heat transter correcting } \\
\text { coefficient of burning gas to } \\
\text { liner wall }\end{array}$ \\
\hline 0 & Retarded injection timing & $A Z 1=-6(C A)$ & $\mathrm{A} Z 1=13(\mathrm{CA})$ & Ignition angle \\
\hline $\mathrm{p}$ & Worn fuel pump plunger & $\begin{array}{l}\mathrm{DAZ}=80(\mathrm{CA}) \\
M=1.0\end{array}$ & $\begin{array}{l}\mathrm{DAZ}=104(\mathrm{CA}) \\
\mathrm{M}=1.3\end{array}$ & $\begin{array}{l}\text { Heat retease duration and } \\
\text { shape factor }\end{array}$ \\
\hline
\end{tabular}




\begin{tabular}{lllll}
\hline $\mathrm{q}$ & $25^{0}$ rudder angle adjusted & $\mathrm{Pe}=73.55(\mathrm{~kW})$ & $\mathrm{Pe}=91.94(\mathrm{~kW})$ & $\begin{array}{l}\text { Effective power of single } \\
\text { cylinder }\end{array}$ \\
\hline $\mathrm{r}$ & 4 class wind encountered & $\mathrm{Pe}=73.55(\mathrm{~kW})$ & $\mathrm{Pe}=110.33(\mathrm{~kW})$ & $\begin{array}{l}\text { Effective power of single } \\
\text { cylinder }\end{array}$ \\
\hline
\end{tabular}

\section{SIMULATED RESULTS}

As thermodynamic variables usually vary within very wide range, the simulated results are normalized in terms of relative deviations $\zeta$ in order to indicate the relations between different thermodynamic variables and performance failures. The term $\xi$ is defined as

$$
\xi=\frac{x-x_{0}}{x_{0}}
$$

The parameters $x_{0}$ and $x$ refer to the thermodynamic variables at normal and abnormal conditions respectively. The calculated relative deviations at rated condition with $450 \mathrm{r} / \mathrm{min}$ engine speed and $441.3 \mathrm{~kW}$ effective power, and at a partial condition with $315 \mathrm{r} / \mathrm{min}$ engine speed and $308.9 \mathrm{~kW}$ effective power are shown in Figure 1 and Figure 2 respectively. From Figure 1 and Figure 2 it is easy to find the variable, which is most sensitive to failure. Several interesting phenomena can be found after further analysis as:

Blocked turbocharger exhaust casing (a) mainly makes decrease in temperature difference $D T_{\mathrm{k}}$ and pressure difference of intercooler air $D p_{\mathrm{k}}$ and slight rise in exhaust manifold temperature $T_{\mathrm{bt}}$ due to higher backpressure of turbocharger. Blocked turbocharger filter (d) makes obvious decrease in pressures of compressor discharge air $p_{\mathrm{k}}$, intake manifold air $p_{\mathrm{s}}$, maximum combustion gas presure $p_{\text {zmax }}$, intercooler air pressure difference $D p_{\mathrm{k}}$ and obvious rise in gas exhaust manifold temperature $T_{\mathrm{bt}}$ due to bigger resistance of air flow and less air/fuel ratio inside chamber.

Poorly cooled cylinder liner (e) and piston cap (f) due to failures from cooling water system have very similar symptoms of obvious rising in compressor discharge temperature $T_{k}$, air intake manifold pressure $p_{s}$, air temperature difference of intercooler $D T_{k}$, maximum combustion gas pressure $p_{z \max }$ and metal temperature of liner or piston cap. This is because poor cooling water takes away less heat and leaves more energy, but cylinder liner has a bigger influence due to its larger cooling surface. Air-blocked inside cylinder jacket $(\mathrm{n})$ reduces its cooling efficiency and hence induces increase in pressure difference $D p_{k}$ and temperature difference $D T_{k}$ of inter-cooler and decrease in fuel consumption ratio $G_{e}$. The symptoms of this failure are like that of poorly cooled cylinder liner due to the same reason.

High inlet cooling water temperature of intercooler $(\mathrm{g})$ due to failures from cooling water system only induces obvious decrease in air temperature 
difference of intercooler $D T_{k}$ and obvious increase in air intake manifold temperature $T_{s,}$, and vice versa (h). Symptoms of fouled intercooler on airside $(\mathrm{k})$ are similar to that of high inlet cooling water temperature failure except for the decrease in pressure difference of intercooler $D p_{k}$. This is due to its less heat exchange efficiency and higher airs flow resistance.

(a) Blocked turbocharger exhaust casing

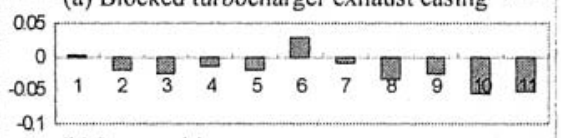

(b) Low ambient temperature

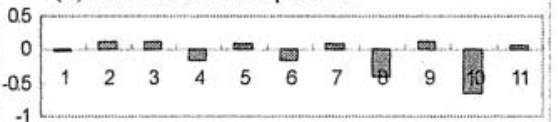

(c) High ambient temperature

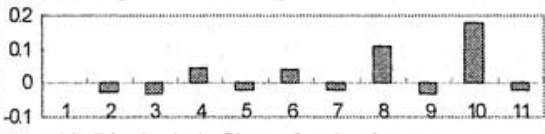

(d) Blocked air filter of turbocharger

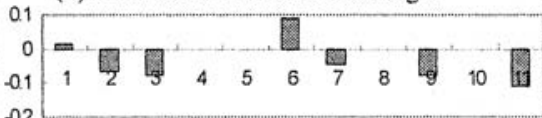

(e) Poorly cooled cylinder liner

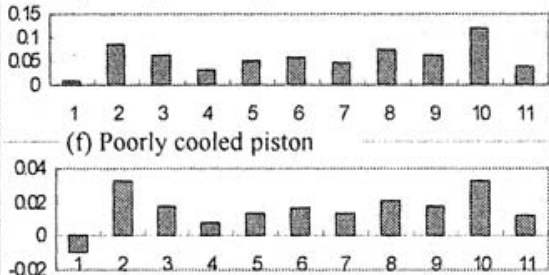

(g) High in cool. water temp. of intercooler

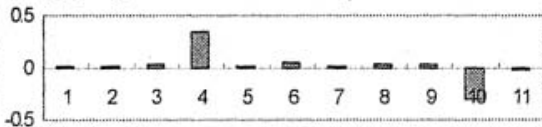

(h) Low in cool. water temp. of intercooler

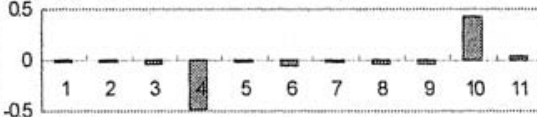

(i) Deposited air intake manifold

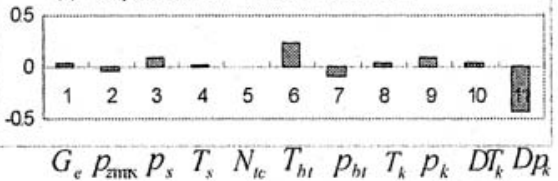

(j) Deposited gas exhaust manifold

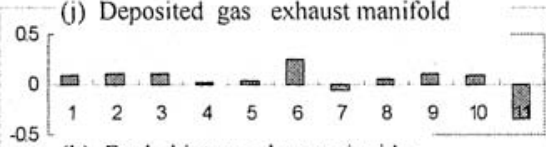

(k) Fouled intercooler on air side

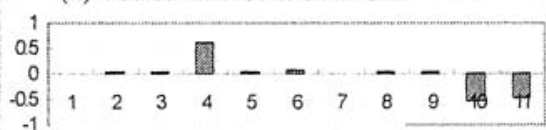

(I) Deposited turbine nozzle

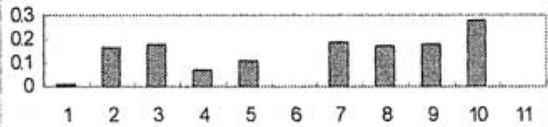

0.02

(m) Worn turbocharger bearing

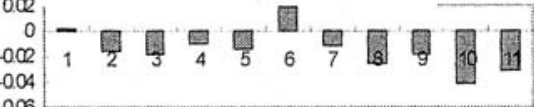

(n) Air-blocked inside cylinder jacket

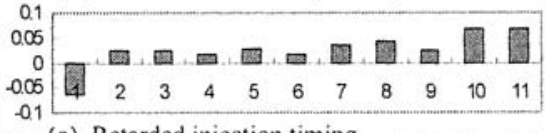

(o) Retarded injection timing

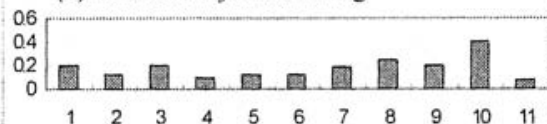

(p) Worn fuel pump plunger

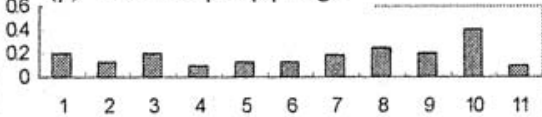

(q) $25^{0}$ rudder angle adjusted

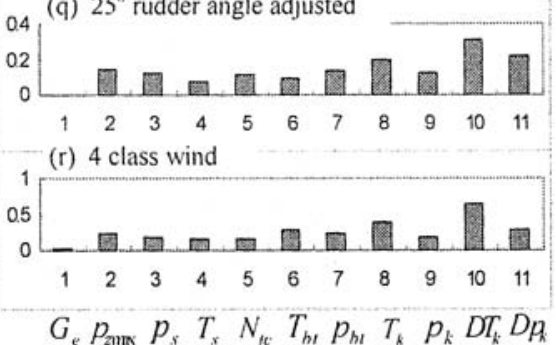

Figure 1 Relative deviation of failures at rated condition

Deposited turbine nozzle (l) increases gas exhaust manifold pressure $p_{b t}$ and turbocharger running speed $N_{k}$. This therefore makes the rise in compressor discharge air temperature $T_{k}$ and pressure $p_{k}$, maximum gas 
combustion pressure $p_{z \max }$ and temperature difference of intercooler $D T_{k}$ due to the increase of circling airflow $G_{k}$. Worn-out turbocharger bearing (m) affects turbocharger's working efficiency and has just a opposite symptom due to the decrease of circling air flow $G_{k}$

(a) Blocked turbocharger exhaust casing

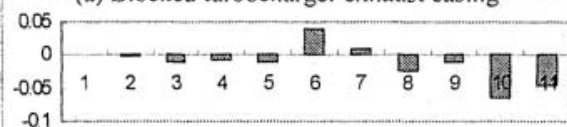

(b) Low ambient temperature

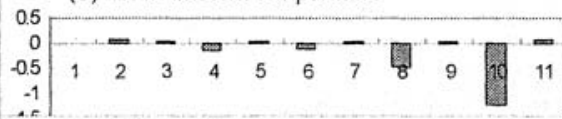

1.5 (c) High ambient temperature

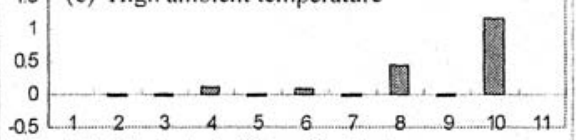

(d) Blocked air filter of turbocharger

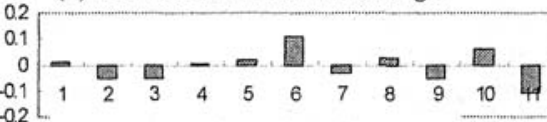

(e) Poorly cooled cylinder liner

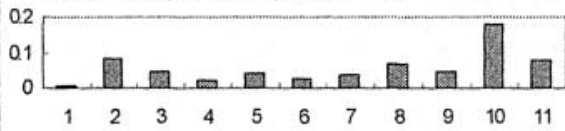

(f) Poorly cooled piston

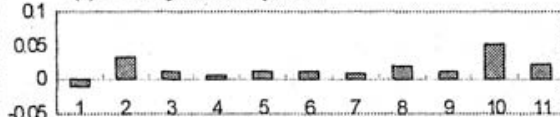

(g) High in cool. water temp. of intercooler

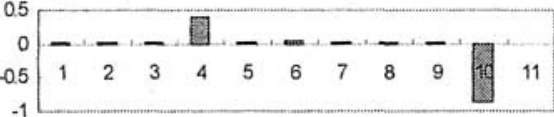

(h) Low in cool. water temp. of intercooler

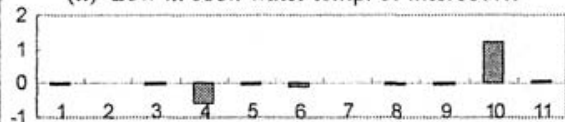

(i) Deposited air intake manifold

$$
\begin{aligned}
& 0.2-\infty \square-\infty \square \\
& \begin{array}{rllllllllll}
-0.2 & 1 & 2 & 3 & 4 & 5 & 6 & 7 & 8 & 9 & 10
\end{array} \\
& -0.4 \mathrm{~L}
\end{aligned}
$$

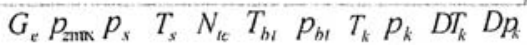

(j) Deposited gas exhaust manifold

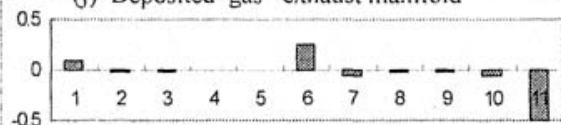

(k) Fouled intercooler on air side

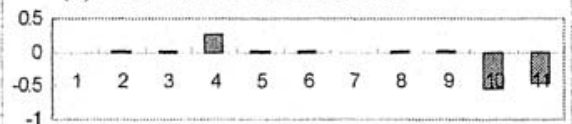

(l) Deposited turbine nozzle

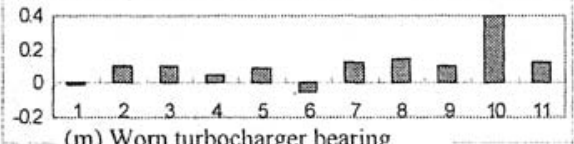

(m) Worn turbocharger bearing

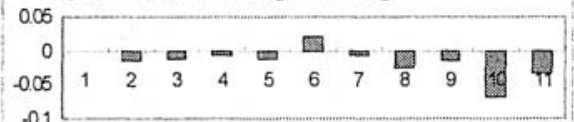

(n) Air-blocked inside cylinder jacket

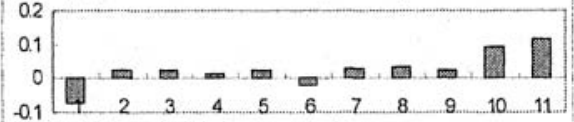

(o) Retarded injection timing

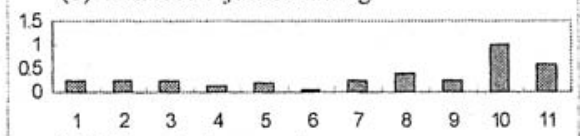

(p) Worn fuel pump plunger

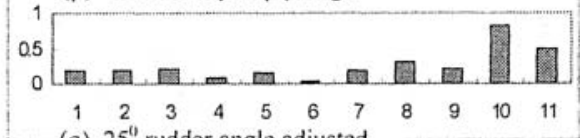

(q) $25^{6}$ rudder angle adjusted

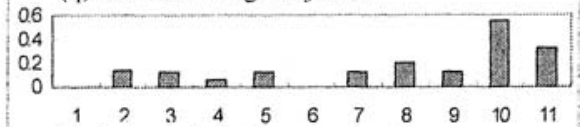

(r) 4 class wind

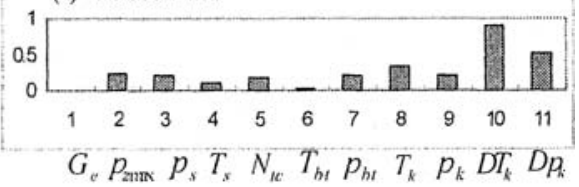

Figure 2 Relative deviation of failures at partial condition

Retarded injection timing ( 0 ) and worn-out fuel pump plunger ( $p$ ) have very similar symptoms of the most obvious rise in temperature difference of intercooler and obvious increase in compressor discharge air temperature $T_{k}$, maximum gas combustion pressure $p_{z \max }$, gas exhaust manifold 
temperature $T_{b l}$ and pressure $p_{b_{l}}$, turbocharger running speed $N_{k}$ and fuel consumption ratio $G_{a}$. This is mainly because the too late injection timing increases the diffusion combustion and worn pump plunger harms the fuel atomization which all worsen the combustion inside combustion chamber. To supply the same power under the same running speed diesel engine needed more fuel and more fresh air.

Ship rudder angle $(q)$ and encountered strong wind (r) during navigation enlarge ship's resistance and need bigger engine power for the same running speed. This brings with the increase in most of variables similar to retarded injection timing and worn fuel pump plunger failures. Ambient temperature (b)(c) has some influence on engine performance. With lower ambient temperature the temperature difference of intercooler $D T_{k}$ descends greatly and compressor discharge air temperature $T_{k}$ drops obviously. So in practical failure diagnosis procedure ship navigation condition and weather condition have to be taken into account.

Comparing Figure 1 and Figure 2, it is found that relative deviations represent very similar trends at rated condition and partial condition. It is implied that relative deviations can be utilized as symptomatic parameters even diesel engine thermodynamic variables usually vary within very wide range at different running conditions. In this way different engine conditions can be taken into account and artificial neural network method can be used in diesel engine failure diagnosis without much modeling work and great difficulty.

Due to the inherent relations beyond diesel engine working principle some variables always have congruent behavior such as compressor discharge air pressure $p_{k}$ and air intake manifold pressure $p_{s}$. It is necessary to make some cancellations of variables to simplify the modeling process in practical failure diagnosis.

\section{FAILURE DIAGNOSIS}

With diesel engine simulation method reference values and symptomatic parameters under different performance failures can be obtained without much experimental modeling. With relative deviation analysis of thermodynamic variables one failure's modeling can be utilized at any probable running condition encountered during ship navigation. By this way artificial neural network can be used in failure diagnosis of marine diesel engine.

Assuming the network input vector, $X \in R^{n}$, the output vector, $Y \in R^{n}$, and the network conjunction weight set $W_{1}(1=1,2, \ldots, L)$ then the artificial neural network can be defined in equation (10) and shown in Figure 3. 


$$
Y=f\left(W_{L} f\left(W_{l,-1} \cdots f\left(W_{1} X\right) \cdots\right)\right)
$$

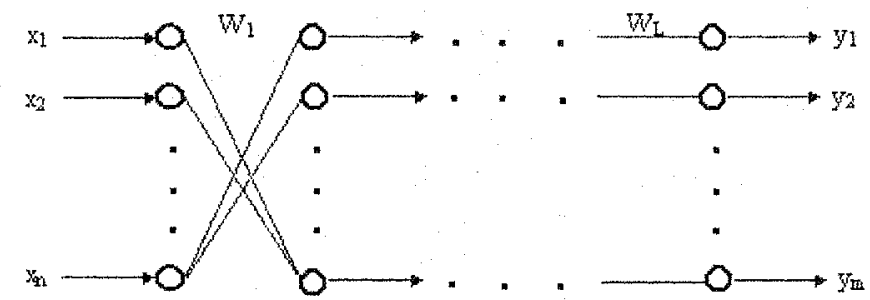

Figure 3 Sketch of the artificial neural network

Then the relative deviations under different failures at partial condition were used as input vector $X$ together with the calculated $W_{1}(1=1,2, \ldots, \mathrm{L})$ as network conjunction weight set. The diagnosis results are shown in Table 2, where values in row $\mathrm{i}$ and column $\mathrm{j}$ indicate the confidence of relative deviation sample $i$ to failure $j$. As can be seen from the diagnosed results (in black) in table 2 that only failure (q) was completely failed to be detected amongest the 18 failures and failures (j), (n), (o) were mistaken as other failures because of their similar symptoms. To get more accurate results, more parameters have to be taken into account such as fuel injection pressure, cylinder liner temperature and superficial vibration signals.

Table2. The diagnosed results with artificial neural network method

\begin{tabular}{|cccccccccccccccccccccc|}
\hline * & \multicolumn{11}{c|}{ Specimen Record code } \\
\hline & $\mathrm{a}$ & $\mathrm{b}$ & $\mathrm{c}$ & $\mathrm{d}$ & $\mathrm{e}$ & $\mathrm{f}$ & $\mathrm{g}$ & $\mathrm{h}$ & $\mathrm{i}$ & $\mathrm{j}$ & $\mathrm{k}$ & $\mathrm{l}$ & $\mathrm{m}$ & $\mathrm{n}$ & 0 & $\mathrm{p}$ & $\mathrm{q}$ & $\mathrm{r}$ \\
\hline $\mathrm{a}$ & $\mathbf{1 . 0}$ & 0 & 0 & 0 & 0 & 0 & 0 & 0 & 0 & 0 & 0 & 0 & 0 & 0 & 0 & 0 & 0 & 0 \\
$\mathrm{~b}$ & 0 & $\mathbf{1 . 0}$ & 0 & 0 & 0 & 0 & 0.01 & 0 & 0 & 0 & 0 & 0 & 0 & 0 & 0 & 0 & 0 & 0 \\
$\mathrm{c}$ & 0 & 0 & $\mathbf{1 . 0}$ & 0 & 0 & 0 & 0 & 0 & 0 & 0 & 0 & 0 & 0 & 0 & 0 & 0 & 0 & 0 \\
$\mathrm{~d}$ & 0 & 0 & 0 & $\mathbf{0 . 9 8}$ & 0 & 0 & 0 & 0 & 0 & 0 & 0 & 0 & 0 & 0 & 0 & 0 & 0 & 0 \\
$\mathrm{e}$ & 0 & 0 & 0 & 0 & $\mathbf{0 . 7 9}$ & 0 & 0 & 0 & 0 & 1 & 0 & 0.81 & 0 & 0 & 0.660 .650 .05 & 0.97 \\
$\mathrm{f}$ & 0 & 0.01 & 0 & 0 & 0.01 & $\mathbf{1 . 0}$ & 0.14 & 0 & 0 & 0 & 0 & 0 & 0 & 1 & 0 & 0 & 0 & 0 \\
$\mathrm{~g}$ & 0 & 0 & 0 & 0 & 0 & 0 & $\mathbf{1 . 0}$ & 0 & 0 & 0 & 0 & 0 & 0 & 0 & 0 & 0 & 0 & 0 \\
$\mathrm{~h}$ & 0 & 0 & 0 & 0 & 0 & 0 & 0 & $\mathbf{1 . 0}$ & 0 & 0 & 0 & 0 & 0 & 0 & 0 & 0 & 0 & 0 \\
$\mathrm{i}$ & 0 & 0 & 0 & 0 & 0 & 0 & 0 & 0 & $\mathbf{1 . 0}$ & 0 & 0 & 0.03 & 0 & 0 & 0 & 0 & 0 & 0 \\
$\mathrm{j}$ & 0 & 0 & 0 & 0 & 0 & 0 & 0 & 0.02 & 0 & $\mathbf{0 . 1 9}$ & 0 & 0 & 0 & 0 & 0 & 0 & 0 & 0 \\
$\mathrm{k}$ & 0 & 0 & 0 & 0 & 0 & 0 & 0 & 0 & 0.02 & 0 & $\mathbf{1 . 0}$ & 0 & 0 & 0 & 0 & 0 & 0 & 0 \\
$\mathrm{l}$ & 0 & 0 & 0 & 0 & 0 & 0 & 0 & 0 & 0.87 & 0 & 0 & $\mathbf{0 . 9 9}$ & 0 & 0 & 0 & 0 & 0 & 0 \\
$\mathrm{~m}$ & 0 & 0 & 0.01 & 0 & 0 & 0 & 0.03 & 0 & 0 & 0 & 0 & 0 & $\mathbf{1 . 0}$ & 0 & .15 & 0 & 0 & 0 \\
$\mathrm{n}$ & 0 & 0 & 0 & 0 & 0 & 0 & 0.01 & 0 & 0 & 0 & 0 & 0 & 0 & $\mathbf{0 . 0}$ & 0.02 & 0 & 0 & 0 \\
0 & 0 & 0 & 0 & 0 & 0 & 0 & 0 & 0 & 0 & 0 & 0 & 0 & 0 & 0.99 & $\mathbf{0 . 0}$ & 0 & 0 & 0 \\
$\mathrm{p}$ & 0 & 0 & 0 & 0 & 0 & 0 & 0 & 0 & 0 & 0 & 0 & 0.02 & 0 & 0 & 0.940 .94 & 0 & 0.06 \\
$\mathrm{q}$ & 0 & 0 & 0 & 0 & 0 & 0 & 0 & 0 & 0 & 0 & 0 & 0 & 0 & 0 & 0 & 0 & $\mathbf{0 . 0}$ & 0 \\
$\mathrm{r}$ & 0 & 0 & 0 & 0 & 0 & 0 & 0 & 0 & 0 & 0 & 0 & 0 & 0 & 0 & 0 & 0 & 0 & $\mathbf{0 . 9 6}$ \\
\hline
\end{tabular}

* Failure Code 


\section{CONCLUSION}

Relative deviation analysis, proposed in this article, is proved to be a good tool for failure analysis of diesel engine thermodynamic variables with different performance failures and under different running conditions. It is easier to find out which variable is the most sensitive to some a failure and which failures have similar symptoms under different running conditions. This will make the modelling quite easier for the large bore diesel engine failure diagnosis with artificial neural network method. Further research is needed to find the similar behaviors between different thermodynamic variables and between different performance failures in order to reduce modelling variables and make the failure diagnosis more practical.

\section{ACKNOWLEDGEMENTS}

This paper was founded by Shanghai Leading Academic Discipline Project (Code: T0603) and supported by Shanghai Education Committee.

\section{REFERENCES}

1. Gu Hongzhong, Marine diesel engine handbook (3), National defense industry press, 1979 (in Chinese)

2. Hu Yihuai, Wan Biyu, Zhan Yulong, Performance failures simulation and informational characters analysis for diesel engine, Transactions of Chinese society for internal combustion engines, Vol. 17, No. 4, 1999 (in Chinese)

3. Gao Xiaohong, Simulation techniques for internal combustion engine, National defense industry press, 1995 (in Chinese)

4. Tang Tianhao etc, A study of integrate intelligent marine monitoring system, Proceedings Of IMECE'97, Shanghai, P. R. China, May, 1997 